\title{
INFLUÊNCIAS DA PANDEMIA NO ENSINO DE MATEMÁTICA: UMA REFLEXÃO SOBRE OS SABERES MOBILIZADOS POR PROFESSORES DO ENSINO MÉDIO
}

\author{
Giovana Rafaela Hasstenteufel ${ }^{\mathrm{x}}$ \\ Karine Pertile ${ }^{2}$
}

RESUMO: Nas últimas décadas muito tem se discutido a respeito do papel do professor no processo de ensino. O professor não pode somente transmitir informações, mas ser mediador entre os alunos e o conteúdo estudado, assumindo o aluno como agente ativo no processo de aprendizagem. Sabemos que cada aluno aprende em tempos e de formas diferentes, por isso a relevância de diferentes metodologias para o ensino da pandemia causada pelo novo Coronavírus (COVID19) as aulas, em 2020, têm sido realizadas através do ensino remoto emergencial, uma alternativa para manter o vínculo com os estudantes e continuar o processo de ensino. Com isso, alunos e professores apresentaram dificuldades, limitações e a certeza de que novos saberes e habilidades precisariam ser mobilizados para tornar o ensino remoto possível. Ao pensar sobre o aprendizado dos alunos e, verificando os índices de desempenho dos estudantes brasileiros com aulas presenciais, a preocupação sobre a qualidade da aprendizagem aumenta ao saber que o ensino remoto ainda não é realidade para muitos alunos, por falta de acesso à Internet ou mesmo computadores. Diante destes dados, professores e instituições tiveram que se reinventar e mobilizar diferentes saberes, para que todos os alunos fossem satisfatoriamente atendidos. Assim, este estudo tem o intuito de responder à seguinte questão norteadora: Que saberes os professores do Ensino Médio precisaram mobilizar para o ensino de Matemática, durante o período do ensino remoto emergencial (ERE)? O objetivo geral é identificar os saberes que os professores do Ensino Médio precisaram mobilizar para o ensino de Matemática durante o ERE.

Palavras- chave: Ensino de Matemática. Ensino Remoto. Docência. Pandemia.

\section{INTRODUÇÃO}

Nas últimas décadas muito tem se discutido a respeito do papel do professor no processo de ensino. $O$ professor não pode somente transmitir informações, mas ser mediador entre os alunos e o conteúdo estudado, assumindo o aluno como agente ativo no processo de aprendizagem. $O$ resultado da avaliação PISA ( $O$ Programa

\footnotetext{
I Instituto Federal do Rio Grande do Sul IFRS Campus Bento Gonçalves E-mail: giovana.rafaela.h@outlook.com.

2 Instituto Federal do Rio Grande do Sul IFRS Campus Bento Gonçalves. E-mail: karine.pertile@bento.ifrs.edu.br.
} 
Internacional de Avaliação de Estudantes) reforça tal afirmação. Esta avaliação ocorre a cada três anos, desde o ano de 2000, e visa informar sobre o desempenho dos alunos de quinze anos de idade as áreas de Ciências, Matemática e Leitura. O Brasil é participante desde o primeiro ano da aplicação desta prova. Ao analisarmos os dados de $2018^{3}$ verificamos que o Brasil aparece na $66^{\circ}$ posição em Ciências, $70^{\circ}$ em Matemática e $57^{\circ}$ em leitura.

Sabemos que cada aluno aprende em tempos e de formas diferentes, por isso a relevância de diferentes metodologias para o ensino. Além disso, como diz afirma Campos (2015, p. 2I), “Abordar de forma diferente, com clareza, os diversos conteúdos matemáticos torna-se fundamental para que o sujeito aprenda a Matemática para a vida e não apenas para os anos escolares.”.

Diante da pandemia causada pelo novo Coronavírus (COVID-I9) as aulas, em 2020, têm sido realizadas através do ensino remoto emergencial, uma alternativa para manter o vínculo com os estudantes e continuar o processo de ensino. Com isso, alunos e professores apresentaram dificuldades, limitações e a certeza de que novos saberes e habilidades precisariam ser mobilizados para tornar o ensino remoto possível. Antes mesmo do distanciamento social, Campos (2015) afirmava que " Devemos procurar alternativas para aumentar a motivação para a aprendizagem. $O$ aluno motivado torna-se um aluno pensante, independente e participativo, logo a indisciplina deixa de existir" (p. 57).

É um período que exige reinvenção: de repente as coisas mudaram e tivemos que nos adaptar ao novo período. Para os professores várias mudanças: adaptar e organizar as aulas para o ensino remoto, além de procurar metodologias diferentes que possam ser utilizadas neste caso. $O$ trabalho realizado por alguns professores acabaram ganhando destaque, como é o caso da professora Rafaela Fabro, uma professora de Matemática do Ensino Médio, de Farroupilha-RS.. Ela utiliza gamificação em suas

3 PISA. Resultados de 2018. Disponível em: https://www.bbc.com/portuguese/brasil-50646695. Acesso em 07 de maio de 2020 . 
aulas e seu material foi muito procurado, principalmente nesta pandemia ${ }^{4}$. Segundo ela, em uma entrevista ao jornal $O$ Informante, a docente relata que

A paixão pela Matemática deve partir do professor, e quem é meu aluno identifica isso diariamente. Temos um grande desafio como professores, de tornar nossas aulas tão atraentes como o celular. Não é fácil e nem sempre é possível. Para aprender Matemática, muitas vezes é necessário 'baixar a cabeça e fazer exercícios', mas também inovar, buscar mostrar a aplicação do conteúdo sempre que possível, utilizando diferentes metodologias, pode motivar os alunos, mesmo se não tiverem tanta facilidade com a disciplina (O INFORMANTE, 2020).

Ao pensar sobre o aprendizado dos alunos e, verificando os índices de desempenho dos estudantes brasileiros com aulas presenciais, a preocupação sobre a qualidade da aprendizagem aumenta ao saber que o ensino remoto ainda não é realidade para muitos alunos, por falta de acesso à Internet ou mesmo computadores. Segundo o Centro Regional de Estudos para o Desenvolvimento da Sociedade da Informação - CETIC, Apenas 42\% das casas brasileiras têm computador; $85 \%$ dos usuários de internet das classes D e E acessam a rede exclusivamente pelo celular e somente $13 \%$ se conectam tanto pelo aparelho móvel quanto pelo computador. No final de 2020 uma notícia repercutiu em grande ênfase nas mídias5: O estudante de Estância Velha, região do Vale do Rio dos Sinos, no Rio Grande do Sul, Alan Somavilla, de II anos, virou notícia por não conseguir assistir as aulas virtuais em sua casa, por não ter sinal de Internet. Pensando nisso, seu pai construiu uma barraca de lona e madeira em sua lavoura, sabendo que lá havia o sinal para seu filho poder estudar. Infelizmente fatos como esse ainda são realidade para muitos brasileiros. Ainda, sobre essa notícia, a diretora do colégio que Alan está matriculado, Giovana Dalcin, enfatiza que tem casos de alunos, além de Alan, que precisam subir em morros e árvores para conseguir sinal e acompanhar as aulas pela plataforma Google Classroom. Conforme os dados apresentados pelo CETIC $^{6}$ :

\footnotetext{
4 A professora Rafaela e seu amor incondicional à matemática. Disponível em: 〈http://www.jornalinformante.com.br/index.php/noticia/a-professora-rafaela-e-seu-amorincondicional-a-matematica $>$. Acesso em 24 set 2020 .

${ }^{5} \mathrm{Pai}$ constrói barraca de madeira e lona para filho acompanhar aulas virtuais no RS. Disponível em: < https://gi.globo.com/rs/rio-grande-do-sul/noticia/2020/o8/24/pai-constroi-barraca-de-madeira-elona-para-filho-acompanhar-aulas-virtuais-em-estrela-velha.ghtml >. Acesso em 24 set 2020.

${ }^{6}$ PESQUISA TIC Domicílios 2018. Disponível em:

https://www.cetic.br/pesquisa/domicilios/indicadores $/$. Acesso em 22 de setembro de 2020.
} 


\begin{abstract}
31,I milhões de brasileiros ( $16 \%$ da população) não têm acesso a água fornecida por meio da rede geral de abastecimento; 74,2 milhões (37\% da população) vivem em áreas sem coleta de esgoto; outros 5,8 milhões não têm banheiro em casa; II,6 milhões (5,6\% da população) vivem em imóveis com mais de 3 moradores por dormitório e 3,5 milhões de pessoas vivem com até $\mathrm{R} \$$ I45 por mês [2]. Falar em qualidade da educação sem olhar para esses dados é quase desumano (CETIC, [2020], s.p.).
\end{abstract}

Diante destes dados, professores e instituições tiveram que se reinventar e mobilizar diferentes saberes, para que todos os alunos fossem satisfatoriamente atendidos. Assim, este estudo tem o intuito de responder à seguinte questão norteadora: Que saberes os professores do Ensino Médio precisaram mobilizar para o ensino de Matemática, durante o período do ensino remoto emergencial (ERE)?

O objetivo geral é identificar os saberes que os professores do Ensino Médio precisaram mobilizar para o ensino de Matemática durante o ERE.

Para atingir o objetivo geral, os seguintes objetivos específicos deverão ser atendidos:

- Identificar quais recursos os professores de Matemática do Ensino Médio estão utilizando para ministrar as aulas remotas;

- Verificar quais dificuldades os professores têm enfrentado para o ensino da Matemática no Ensino Médio;

- Conhecer a percepção dos professores em relação as mudanças que afetaram seu trabalho;

- Descrever as principais alterações do trabalho docente que acarretaram maior flexibilização diante da pandemia;

- Analisar os impactos das mudanças provocadas diante da pandemia sobre os aspectos da sobrecarga de trabalho e das jornadas estendidas.

- Saber como os professores têm organizado seu tempo para cumprir com as tarefas docentes e suas atividades pessoais.

\title{
2 METODOLOGIA
}


Como metodologia, para desenvolver o seguinte trabalho, terei como embasamento teórico notícias disponíveis na internet referentes ao tema. Além disso, serão aplicados questionários aos professores de Matemática do Instituto Federal de Educação, Ciência e Tecnologia do Rio Grande do Sul (IFRS). Com o questionário, pretende-se saber como os professores percebem o trabalho docente durante o ERE.

Os dados produzidos com os questionários serão analisados à luz da Análise de Conteúdo (BARDIN, 2016). A análise dos dados vai ser agrupada em duas escalas semelhantes, uma sobre "as principais dificuldades vivenciadas no ensino neste momento de pandemia" e a outra destinada a identificar "quais recursos os professores estão utilizando no ensino remoto”. Será destacado termos referentes a sobrecarga de trabalho. A maneira como cada um deles se ajustou durante todo esse processo será relatado, ou seja, citar quais foram as mudanças que eles tiveram que se adaptar e quais recursos estão utilizando nas aulas remotas.

\section{REFERENCIAL BIBLIOGRÁFICO}

\section{I ENSINO REMOTO: DIFICULDADES E DESAFIOS ENFRENTADOS PELOS PROFESSORES}

É de suma importância refletir sobre o trabalho do professor, principalmente tendo em vista a situação atual. Não houve preparação para esse momento e de fato, a maioria das pessoas está passando por momentos que exigem mudanças nos hábitos e a necessidade de inovação, pois a realidade para muitos é de trabalhar em casa.

Quando se pensa na educação esse processo é ainda mais complexo. Não existe mais o contato físico entre professor e aluno, algo extremamente necessário. Quando de forma presencial, o professor observa as suas turmas para perceber quais são suas dúvidas e o que está funcionando no processo de ensino e o que precisa mudar, mas agora houve um rompimento dessa socialização, dificultando esse mecanismo. Segundo Campos (2015)

A comunicação é tão importante que se torna um instrumento que expressa o pensamento, produzindo mudanças na estrutura cognitiva do indivíduo, 
reestruturando diversas funções psicológicas, como a memória, a atenção voluntária e a formação de conceitos (p. i8).

O ensino remoto trouxe desafios para os alunos e seus familiares, mas quando se pensa no trabalho do professor, essa tarefa é ainda maior. Ele precisa dar aulas e orientar as famílias, sem esquecer, no entanto, da vida pessoal e seus afazeres domésticos.

As novas formas de ensino, por meio de aplicativos e plataformas digitais, também exigiram dos professores uma exigência que não é profissional, mas sim econômica. Muitos professores tiveram que investir em uma capacidade maior de internet e melhorar seu computador e smartphone, custos esses que não são divididos com a escola. Além disso, foi necessário aos professores um novo saber: o conhecimento tecnológico e pedagógico do conteúdo.

Quando falamos sobre conhecimento do conteúdo refere-se ao conhecimento sobre algum conhecimento que vai ser ensinado ou aprendido. Desta forma, é tarefa do professor compreender e ter conhecimento sobre as disciplinas que ele vai ensinar, então precisam estar cientes sobre os fatos, conceitos, teorias e os procedimentos,

também as conhecer as estruturas explicativas para poder organizar e conectar as ideias que envolvem suas disciplinas (KOEHLER, 2006).

O conhecimento pedagógico refere-se a analisar de forma mais profunda sobre técnicas ou métodos para trazer para sala de aula. E, ainda, o uso de outras estratégias para usar como forma de avaliação aos seus alunos. Segundo Koeheler (2006) “(...) um professor com profundo conhecimento pedagógico entende como os alunos constroem conhecimento, adquirem habilidades e desenvolvem hábitos mentais e disposições positivas para o aprendizado"

O conhecimento de conteúdo pedagógico envolve saber sobre qual abordagem se torna viável em relação a determinado conteúdo e isso exige do professor saber como organizar esse conteúdo da melhor forma possível para trabalhar com seus alunos. (KOEHLER, 2006).

Por diversas vezes o professor de matemática é confundido com um matemático. Um dos motivos disso acontecer pode ser o fato de existir uma ligação 
entre a docência na escola com as ciências universitárias matemáticas. Vale ressaltar também que existe diferença entre educador matemático e professor de matemática. O educador domina a matemática para ensinar e a matemática a ensinar. Já o segundo acredita na existência de apenas uma Matemática para ensinar aos seus alunos, desconhece a matemática para ensinar. (VALENTE,2017).

O conhecimento tecnológico envolve o quadro, giz e também algo mais avançado, como o uso da internet e tudo que ela nos possibilita. $\mathrm{O}$ uso da internet requer conhecimentos mais específicos, como hardware e sistemas operacionais, e também conhecimentos que envolvam textos, planilhas, instalar/desinstalar aplicativos, entre outros (KOEHLER, 2006).

Existe também o conhecimento de conteúdo tecnológico, que seria aliar tecnologia com o conteúdo. E quanto mais recente, mais possibilidades ela nos oferece, com uma melhor representação e flexibilidade. E esse avanço na tecnologia traz como tarefa aos professores encontrar os conteúdos que podem ser mudados pela aplicação tecnológica, permitindo uma visualização melhor do que está sendo ensinado e garantindo a sua melhor compreensão (KOEHLER, 2006).

Sobre conhecimento tecnológico pedagógico pode-se dizer que seria os professores utilizarem os instrumentos tecnológicos na sua prática docente, seja em registros de classe, frequência e notas ou, também fóruns de discussão e salas de batepapo (KOEHLER, 2006).

Para finalizar, o conhecimento de conteúdo tecnológico pedagógico é algo mais amplo e envolve técnicas pedagógicas para explicar conteúdos com o uso da tecnologia. Inclui a habilidade de ver como as tecnologias podem ser aplicadas para a construção do conhecimento, ou ainda, desenvolver e fortalecer as aprendizagens que o aluno já possui. (KOEHLER, 2006).

Em maio de 2020, o site Nova Escola, realizou uma pesquisa7 com o título: "A situação dos professores no Brasil durante a pandemia”. Esta pesquisa contou com 8,I mil respostas de professores da Educação Básica. Porém, os dados obtidos refletem

7 Disponível em:< https://novaescola.org.br/conteudo/r940I/ansiedade-medo-e-exaustao-como-aquarentena-esta-abalando-a-saude-mental-dos-educadores $>$. Acesso em: 05 de novembro de 2020. 
certa preocupação, como conclusão desta pesquisa obteve-se que: "apenas 8\% declararam se sentir ótimos ao comparar sua saúde emocional com o período prépandemia. Outros $28 \%$ a consideraram péssima ou ruim neste momento e $30 \%$ classificam como razoável”. (NOVA ESCOLA, 2020). E os mesmos se consideram cansados, ansiosos, estressados e vivendo uma fase com muita cobrança, desenvolvendo insegurança. (NOVA ESCOLA, 2020).

Outra pesquisa que reflete sobre isso foi desenvolvida pelo Instituto Península e divulgada pelo $\mathrm{GI}^{8}$ e mostra que houve uma queda entre os professores que antes se sentiam calmos e satisfeitos, esta pesquisa foi realizada com 3,8 mil professores. (GI, 2020). Os dados obtidos, analisando a variação dos meses de maio e agosto constam no gráfico abaixo:

\footnotetext{
${ }^{8}$ Gı é um portal de notícias brasileiro mantido pelo Grupo Globo e sob orientação da Central Globo de Jornalismo. Fonte: Wikipedia. Disponível em:< https://pt.wikipedia.org/wiki/Gr . Acesso em os de novembro de 2020 .
} 


\section{Percepção dos professores na pandemia, em \%}

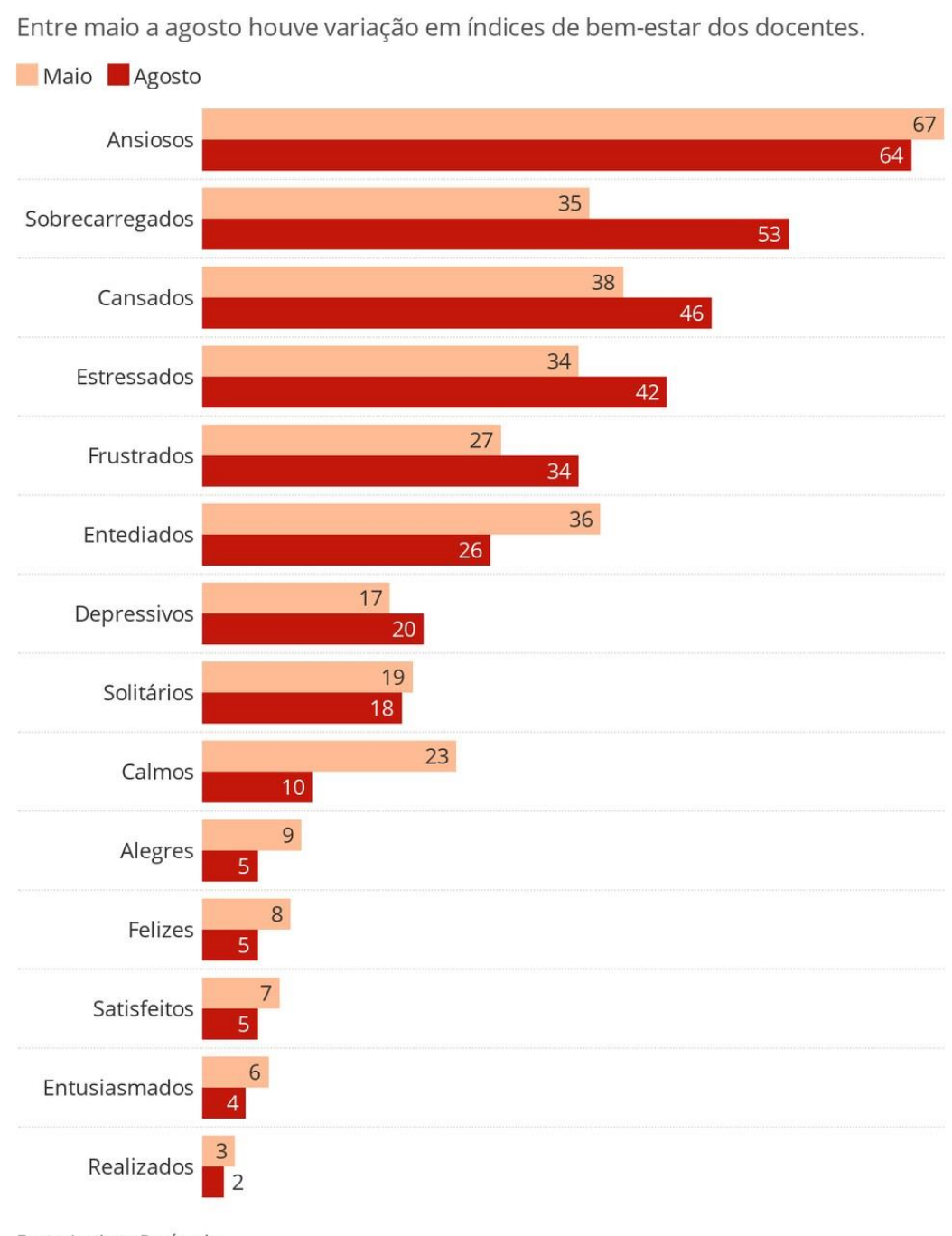

Também outra informação bastante importante dessa pesquisa é sobre a percepção dos professores sobre a volta às aulas. Pensando na reabertura das escolas eles poderiam responder seguindo uma escala de o a 5 . Considerando próximo de zero como "nada confortável" e próximo de 5 como "muito confortável" e a média obtida nessa pesquisa foi de $\mathrm{I}, 07$, considerando tanto a rede pública como particular.

Com base nesses dados e considerando essa situação muito preocupante, e ainda tendo em vista que não se sabe uma data para as aulas voltarem a acontecer normalmente, de forma presencial, pretende-se aplicar um questionário com diversos professores da Educação Básica, com perguntas referentes ao tema. 
ANÁLISE DOS DADOS

\begin{tabular}{|c|c|c|c|c|}
\hline Professor & Idade & Gênero & $\begin{array}{l}\text { Há quanto tempo você é professor (a) de } \\
\text { Matemática? }\end{array}$ & $\begin{array}{l}\text { Há quanto tempo você é } \\
\text { professor(a) na rede federal } \\
\text { de ensino? }\end{array}$ \\
\hline Professor A & $\begin{array}{l}\text { De 3I a } 40 \\
\text { anos }\end{array}$ & $\mathrm{M}$ & De 16 a 20 anos & De 5 a io anos \\
\hline Professor B & $\begin{array}{l}\text { De 3i a } 40 \\
\text { anos }\end{array}$ & $\mathrm{M}$ & De 5 a io anos & Menos de 5 anos \\
\hline Professora C & $\begin{array}{l}\text { De 3I a } 40 \\
\text { anos }\end{array}$ & $\mathrm{F}$ & De i6 a 20 anos & De iI a is anos \\
\hline Professor D & $\begin{array}{l}\text { De } 4 \mathrm{I} \text { a } 50 \\
\text { anos }\end{array}$ & $\mathrm{M}$ & De 5 a io anos & De iI a is anos \\
\hline Professor E & $\begin{array}{l}\text { De 31 a } 40 \\
\text { anos }\end{array}$ & $\mathrm{M}$ & Menos de 5 anos & Menos de 5 anos \\
\hline Professor F & $\begin{array}{l}\text { De 31 a } 40 \\
\text { anos }\end{array}$ & M & De 5 a io anos & Menos de 5 anos \\
\hline Professor G & $\begin{array}{l}\text { De } 4 \mathrm{I} \text { a } 50 \\
\text { anos }\end{array}$ & $\mathrm{M}$ & Mais de 20 anos & De iI a is anos \\
\hline Professora H & $\begin{array}{l}\text { De } 41 \text { a } 50 \\
\text { anos }\end{array}$ & F & De i6 a 20 anos & De 5 a io anos \\
\hline Professora I & $\begin{array}{l}\text { De 31 a } 40 \\
\text { anos }\end{array}$ & F & De 5 a io anos & De 5 a io anos \\
\hline Professor J & $\begin{array}{l}\text { De 3I a } 40 \\
\text { anos }\end{array}$ & $\mathrm{M}$ & De 16 a 20 anos & Menos de 5 anos \\
\hline Professora $\mathrm{K}$ & $\begin{array}{l}\text { De 31 a } 40 \\
\text { anos }\end{array}$ & F & De 5 a io anos & Menos de 5 anos \\
\hline Professor L & $\begin{array}{l}\text { De 3I a } 40 \\
\text { anos }\end{array}$ & $\mathrm{M}$ & De iI a is anos & Menos de 5 anos \\
\hline Professor M & $\begin{array}{l}\text { De } 4 \mathrm{I} \text { a } 50 \\
\text { anos }\end{array}$ & $M$ & Mais de 20 anos & De 5 a ro anos \\
\hline Professora $\mathrm{N}$ & $\begin{array}{l}\text { De 3I a } 40 \\
\text { anos }\end{array}$ & $\mathrm{F}$ & De 16 a 20 anos & De in a is anos \\
\hline
\end{tabular}

Através da aplicação do questionário aos professores obteve-se o seguinte resultado.

A primeira pergunta sobre o Ensino Remoto Emergencial pedia para os professores definirem esse momento. Segundo (APPENZELLER; MENEZES; SANTOS; PADILHA; GRAÇA; BRAGANÇA, 2020): "Ensino remoto emergencial é caracterizado pela mudança temporária do ensino presencial para o ensino remoto". 
O professor A definiu como exaustivo e sem retorno dos estudantes. Se sente angustiado em saber se os alunos estão aprendendo ou não. $O$ professor $B$ comenta que foi uma ferramenta necessária ao momento que estamos vivendo e que foi preciso se reinventar para aproximar o ensino a distância do presencial. Também diz que nada substitui as trocas da sala de aula. Nesse sentido também pensa o professor F, para ele é como uma lástima, mas necessário. Para completar, para o professor $M$ é um momento necessário e um bom momento de reflexão sobre as práticas de ensino.

A professora C diz que é um momento peculiar, "muitos impactos em diferentes aspectos na vida de professores e estudantes, o ERE é uma parte de tudo isso”. Além disso, comenta que é um desafio pensar práticas e atividades para o ensino de Matemática nesse formato e nesse contexto. $O$ professor $D$ completa afirmando que para ele é um momento extremamente prejudicial para todos, em especial para os discentes.

Este momento exige do professor novas tarefas, ele precisa se adequar há um modo de ensino diferente do que estava acostumado. Exatamente sobre isso (MOREIRA; HENRIQUES; BARROS, 2020) relata que:

A virtualização dos sistemas educativos a que neste momento estamos sendo obrigados a efetuar pressupõe a alteração dos seus modelos e práticas e "obriga" o professor a assumir novos papéis, comunicando de formas com as quais não estava habituado. (MOREIRA; HENRIQUES; BARROS, 2020)

Para o professor E este momento é extraordinário. $O$ professor $G$ comenta o seguinte "Um momento para reinventar a docência e também que demanda dos alunos reaprender a aprender e estudar.”. Já a professora H definiu esse momento como uma situação complexa e que demanda cuidados.

De acordo com a professora I é: "Um momento de novos aprendizados. Momento para rever nossas práticas e adaptá-las às mudanças da realidade.”. Professor J vê como um grande desconforto. Já para a professora $\mathrm{K}$ e para a professora $\mathrm{N}$, é um momento desafiador. 
O professor L pensa o seguinte: "É um momento completamente singular onde todos tivemos que nos reinventar e repensar nossas práticas. Migrando para um formato diferente do que conhecíamos e adaptando práticas que não eram adequadas.”.

Quando questionados se já havia ministrado aulas de forma remota antes da pandemia e se consideravam preparados para tal, nenhum dos professores havia ministrado aulas de forma remota. E, apenas os professores $\mathrm{K}$ e $\mathrm{L}$ se sentiram preparados.

A terceira pergunta pretende saber se os docentes encontraram desafios no ERE? Em caso positivo, pede para citar quais foram eles.

O professor A relata a falta de retorno dos estudantes e na preparação das aulas e dos materiais. O professor B disse que, inicialmente um dos desafios é a utilização dos métodos, mas que esse já foi superado. Porém, um desafio que ainda persiste é a falta de participação dos alunos. Nesse sentido, o professor $F$ também comenta sobre a dificuldade em garantir comprometimento nos estudos e fazer com que a avaliação realmente fosse efetiva.

Como maiores desafios, a professora $\mathrm{C}$ cita a questão do tempo destinado as atividades. "É preciso selecionar objetivos e adaptar as atividades para o tempo disponível e para as possibilidades de acesso dos estudantes”. Também, o professor D destaca absoluta falta de tempo para preparo de aulas, vídeos, etc. Assim como o professor E que indica a rotina de aulas e a preparação didática como os principais problemas.

O professor $\mathrm{G}$ e a professora $\mathrm{N}$ destacam como maiores desafios a adequação e a adaptação dos conteúdos ao novo formato. Para a professora $\mathrm{H}$ entre os desafios está manter os alunos conectados cognitivamente na aula. Já para a professora I, o maior desafio é a adaptação de materiais de aula, de forma a atingir os estudantes.

Para o professor $\mathrm{J}$ foi um desafio manejar ferramentas de áudio e vídeo. $\mathrm{O}$ professor L considerou criar um laço com estudantes sem o contato presencial. Assim como o professor $\mathrm{M}$ destacou criar alternativas as interações professor-aluno. 
A professora $\mathrm{K}$ não encontrou desafios.

O ambiente virtual de ensino e aprendizagem adotado para todos os professores foi o Moodle e apenas o professor J teve problemas com a sua utilização.

Agora a comunicação entre os alunos e entre os alunos e o professor também ocorre através do ambiente virtual. Portanto, é de suma importância que esse ambiente seja organizado. Deve conter um item para colocar os avisos, outro para que os alunos insiram suas dúvidas e também dedicar um item para conversas e recados de forma mais descontraída. Além disso, selecionar um tópico para cada tema diferente. (MOREIRA; HENRIQUES; BARROS, 2020)

A próxima pergunta diz respeito aos recursos utilizados pelos professores no ensino remoto.

Os recursos utilizados pelo professor A foram: Meet, power point e vídeos. O professor B citou Meet e vídeos e comenta que comprou uma mesa digitalizadora. A professora $C$ utilizou material textual, vídeos e materiais de sites da internet. Já o professor D somente utilizou Moodle e Meet.

Para o professor E, Videoaulas e resumos em pdf foram aqueles utilizados. O professor F destacou Moodle, Meet, e-mail, WhatsApp. Os recursos pontuados pela professora $\mathrm{H}$ foram Moodle, Meet, WhatsApp e outros aplicativos de interação e comunicação.

Segundo a professora I, os recursos utilizados foram: Moodle e Meet, YouTube. Já para o professor J foram os seguintes: Notebook, mesa digitalizadora, Google Meet, internet.

Aqueles citados pela professora K são: Questionários, chats, fóruns, aulas gravadas. Gravação de videoaulas, aulas por videoconferência, quadro virtual e hardware mesa digitalizadora foram citados pelo professor L. O professor M utilizou textos, vídeos, questionários, tarefas, Meet e softwares educacionais. Segundo a professora $\mathrm{N}$, os recursos utilizados foram: Questionários, tarefas, aulas gravadas e Meet. 
O professor $\mathrm{G}$ não entendeu a pergunta.

A próxima pergunta é sobre os conhecimentos adquiridos neste processo.

O professor A cita que obteve conhecimento em relação aos recursos para utilizar na forma remota. O professor B se atualizou no período sem aulas, buscando conhecimentos de ferramentas digitais. Já a professora $\mathrm{C}$ obteve conhecimentos a em repensar as práticas docentes para atuação nesse formato, elaboração de materiais para disponibilizar aos estudantes, pensar atividades que o estudante possa ser mais autônomo durante o processo de aprendizagem.

Como conhecimento adquirido cita o professor E: "Diferentes formas de atingir o discente, coisa que passa desapercebido durante as aulas "normais". " O professor G cita o seguinte: "Conheci melhor os alunos e as dificuldades, principalmente sociais e econômicas dos alunos. Também foi possível perceber com facilidade a influência do "econômico".

A professora $\mathrm{H}$ comenta que somente aprendeu a usar alguns aplicativos. Assim como a professora I que aprendeu a elaborar e publicar vídeos no YouTube. Nesse sentido também comenta o professor J dizendo que melhorou os conhecimentos sobre áudio e vídeo. O professor L cita o funcionamento de AVEAs, conhecimentos técnicos de softwares de gravação e edição de vídeos. Segundo o professor $M$ também aprendeu a elaborar vídeos e utilizar a mesa digitalizadora.

Dentre os conhecimentos adquiridos pela professora $\mathrm{N}$ ela destaca que foram muitos, mas que, para ela o mais desafiador foi conseguir manter a frequência de acesso dos estudantes aos materiais disponibilizados num curto espaço de tempo, tendo em vista que no campus Restinga a cada 4 ou 5 semanas fechavam um trimestre.

Dentre os conhecimentos adquiridos pela professora K estão: procurar mais os alunos. Indo mais atrás deles.

Os professores $\mathrm{D}$ e $\mathrm{F}$ comentaram que não adquiriram conhecimento em relação à atividade docente. Todos os professores estão no modo de ensino $100 \%$ remoto. 


\section{REFERÊNCIAS}

OLIVEIRA, Junia. Ensino remoto é prova de fogo também para professores. Disponível em:https://www.em.com.br/app/noticiainterna_gerais,I183063/ensinoremoto-e-prova-de-fogo-tambem-para-professores.shtml. Acesso em: 28 out. 2020.

BR, Cetic. TIC Domicílios 2018 revela que 40,8 milhões de usuários de Internet utilizam aplicativos de táxi ou transporte. Disponível em: https://cetic.br/noticia/ticdomicilios-2018-revela-que-40-8-milhoes-deet-utilizam-otransporte/. Acesso em: 26 set. 2020 .

G. Cresce percentual de professores que se dizem sobrecarregados, cansados e estressados durante a pandemia, aponta levantamento. Disponível em: https://gi.globo.com/educacao/noticia/2020/o8/3I/cresce-percentual-de-dizemsobrecarregados-cansados-e-estressados-durante-a-pandemia-apontalevantamento.ghtml. Acesso em: o5 nov. 2020.

SALAS, Paula. Ansiedade, medo e exaustão: como a quarentena está abalando a saúde mental dos educadores. Disponível em: https://novaescola.org.br/conteudo/I940I/ansiedade-medo-e-exaustao-como-aquarentena-esta-abalando-a-saude-mental-dos-educadores. Acesso em: 05 nov. 2020.

CAMPOS, Ana Maria Antunes de. Discalculia: Superando as dificuldades em aprender Matemática. Rio de Janeiro: Wak Editora, 2015.

CAMPOS, Ana Maria Antunes de. JOGOS MATEMÁTICOS: uma nova perspectiva para discalculia. Rio de Janeiro: Wak Editora, 2015. 96 p.

INFORMANTE, Jornal O. A PROFESSORA RAFAELA E SEU AMOR INCONDICIONAL À MATEMÁTICA. Disponível em: http://www.jornalinformante.com.br/index.php/noticia/a-professora-rafaela-e-seuamor-incondicional-a-matematica. Acesso em: 24 set. 2020.

BARDIN, Laurence. Análise de Conteúdo. São Paulo: Edições 7o, 2016.

APPENZELLER, Simone; MENEZES, Fábio Husemann; SANTOS, Gislaine Goulart dos; PADILHA, Roberto Ferreira; GRAÇA, Higor Sabino; BRAGANÇA, Joana Fróes. Novos Tempos, Novos Desafios: Estratégias para Equidade de Acesso ao Ensino Remoto Emergencial. 2020. 6 f. - Revista Brasileira de Educação Médica, 2020.

VALENTE, Wagner Rodrigues. Os saberes para ensinar matemática e a profissionalização do educador matemático. 2017. 222 f. - Universidade Federal de São Paulo, São Paulo, 2017. 